\section{Andamios Revista de Investipación Social}

\section{Andamios. Revista de Investigación Social} ISSN: 1870-0063

revistaandamios@uacm.edu.mx

Universidad Autónoma de la Ciudad de México México

Choay, Françoise; Urrieta García, Salvador

EL REINO DE LO URBANO Y LA MUERTE DE LA CIUDAD

Andamios. Revista de Investigación Social, vol. 6, núm. 12, diciembre, 2009, pp. 157-187

Universidad Autónoma de la Ciudad de México

Distrito Federal, México

Disponible en: http://www.redalyc.org/articulo.oa?id=62815957008

Cómo citar el artículo

Número completo

- Más información del artículo

- Página de la revista en redalyc.org

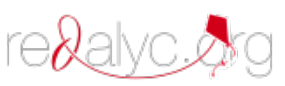

Sistema de Información Científica

Red de Revistas Científicas de América Latina, el Caribe, España y Portugal

Proyecto académico sin fines de lucro, desarrollado bajo la iniciativa de acceso abierto 


\title{
EL REINO DE LO URBANO Y LA MUERTE DE LA CIUDAD
}

\author{
Françoise Choay \\ Traducción del francés: \\ Salvador U rrieta García*
}

INTRODUCCIÓN DEL TRADUCTOR

La ciudad ha sido el elemento articulador de las sociedades en el tiempo. Muchas de estas ciudades, las Ilamadas históricas, dan cuenta de los progresos y retrocesos de las civilizaciones que constituyen hoy la esencia de la historia del mundo, y que también hoy nos ofrecen una herencia invaluable, misma que identificamos como patrimonio cultural.

Estas herencias culturales tienen en muchos lugares del planeta un papel protagónico, pero con el riesgo de ser sacralizadas o banalizadas. Frente a esta doble posibilidad, Françoise Choay nos ofrece una reflexión sobre la idea de ciudad y su relación con el fenómeno urbano, que nos puede ayudar a comprender la importancia y el papel de los centros antiguos o de las ciudades históricas en este mundo complejo, aparentemente perturbado por la civilización de la cibernética y del mercantilismo. Se pone en tela de juicio la competencia de quienes hoy buscan conceptualizar y construir el espacio habitable, principalmente en un mundo globalizado, que parece perder los rasgos humanos.

El artículo que a continuación se presenta forma parte de un libro que compendia las contribuciones que Françoise Choay ha realizado durante más de dos décadas sobre "las figuras múltiples de la espacialización y su historia" y se presenta bajo el título de "Para una antropología del espacio". ${ }^{1}$ La elección de este artículo fue una tarea difícil dada la posibilidad que

\footnotetext{
* Ingeniero-Arquitecto, Maestro y Doctor en Urbanismo. Profesor investigador en la Escuela Superior de Ingeniería y Arquitectura (ESIA), del Instituto Politécnico N acional (IPN). Orienta sus trabajos a los campos de la Conservación U rbano-Arquitectónica y del Espacio Público y es miembro del Consejo Internacional de Sitios y M onumentos (Icomos). ${ }^{1}$ Choay F. (2006), Pour une Anthropol ogie del'Espace, París: Éditions du Seuil, pp. 165-198.
} 
nos ofreció la autora de escoger uno de entre tanta riqueza conceptual que ofrece este texto y que sin duda es una referencia obligada, no sólo para los estudios urbanos, sino para otras muchas disciplinas afines (arquitectura, historia del arte, sociología, filosofía, etcétera).

Agradezco a mi muy estimada profesora su generosidad y confianza para traducir este artículo, lo cual representa un delicado trabajo de interpretación de ideas y de mensajes que espero haber cumplido formalmente.

EL REINO DE LO URBANO Y LA MUERTE DE LA CIUDAD ${ }^{2}$

Françoise Choay**

Europa es hoy triunfalmente urbana. En ella, el espacio rural y las poblaciones rurales se reducen cada día en tanto que se multiplica el número de megalópolis, conurbaciones, comunidades urbanas, tecnópolis y tecnopolos.

Ciudad ha devenido una palabra clave de la tribu política, una palabra que le sirve para todo a la tribu mediática, la palabra coartada de los clanes de urbanistas, de "amenageurs", ${ }^{3}$ de arquitectos, de administradores, de sociólogos que la escudriñan, la auscultan y/o pretenden darle forma. ¿Pero "urbanización" es sinónimo de "producción de ciudad"?

La situación actual es el resultado de una transformación de la ciudad europea que se efectuó de manera sensible entre los años de 1850 y

\footnotetext{
${ }^{2}$ Contribución a (1994), La Ville, art et architecture en Europe, 1870- 1993 (catál ogo de la exposición quetuvo lugar en el Centro Pompidou), París: Editions du Centre Pompidou. ** Estudió filosofía, dirigió el Instituto de Urbanismo en la Universidad de París vill. Desde la década de 1950 se ha dedicado al estudio del urbanismo, el patrimonio edificado y la arquitectura. Es autora de más de una docena de libros especializados. En 1995 el Estado francés le otorgó el Gran Premio N acional del Patrimonio y en 2007 recibió el Premio del libro de Arquitectura por Pour une anthropologie de l'espace. A pesar de ser una prolífica autora, reconocida en Europa y América, sólo han aparecido dos libros suyos en español: (1970) [1964], El urbanismo, utopías y realidades, y (2007) [1992], Alegoría del Patrimonio.

${ }^{3}$ Vocablo inexistente en español y que denota un profesional que reordena o recompone el espacio urbano. [N ota del traductor].
} 
nuestra época. En el mapa de Europa, encontramos los mismos nombres que en la Edad Media, admiramos el largo periodo de duración de estas construcciones urbanas que tienen por nombre París, Nápoles, Londres, Milán, pero también Barcelona, Praga, Zurich... y nos maravillamos de la vitalidad actual de los antiguos racimos de ciudades medievales, hanseáticas ${ }^{4}$ o flamencas.

No obstante en el curso de un poco más de un siglo no es una evolución banal lo que se ha llevado a cabo, sino una mutación que esconde la permanencia de las palabras y de las toponimias. En nuestra civilización de la imagen es suficiente mostrar visualmente las consecuencias, para comprender cabal mente la naturaleza de esta mutación, su amplitud y su historia.

Con este fin, la exposición del Centro Pompidou confronta dos series de representaciones. Unas emanan de practicantes, arquitectosurbanistas y otras de artistas. Las primeras al servicio de la acción, de la ideología y algunas veces del sueño, son proyectos, realizados o no. Las segundas registran la metamorfosis del campo urbano con una sensibilidad de sismógrafo. No nos equivoquemos. No se trata aquí de la ilustración, sino de la videncia, privilegio de los artistas quienes revelan y dan cuerpo a los fenómenos. Así, pintores, grabadores, fotógrafos y cineastas nos confrontan, desde el fin del siglo xIx, con una ciudad bifronte: benéfica según unos, efigie del progreso y de la belleza, fermento de la vida social hasta en el anonimato de las masas; maléfica según otros, sinónimo de caos, de perversión, de un desamparo y de una fealdad, en fin, que la estética soberana del cine ha sabido apropiarse. No obstante, a medida que pasa el tiempo, tanto unos como otros designan de manera semejante la acumulación progresiva de personas, la multiplicación de los trayectos y la aceleración de la velocidad, el gigantismo contagioso de las construcciones verticales y horizontales, la diseminación periférica y para acabar, una figura: la de la ausencia.

\footnotetext{
${ }^{4}$ Referente a la Liga H anseática (H anse, en alemán; hanse en sueco), que fue una federación de ciudades del norte deAlemania y de comunidades de comerciantes al emanes en el mar Báltico, los Países Bajos, Noruega, Suecia, Inglaterra, Polonia, parte de Finlandia y Dinamarca, así como regiones que ahora se encuentran en Estonia y Letonia. [N ota del editor].
} 
La mirada sucesiva y convergente de los pintores, fotógrafos y cineastas nos pone en alerta contra las palabras. La secuencia de sus presentaciones obliga a preguntarse si la divinidad bifronte, esta ciudad madre y castrante, hoy invocada y conjurada con pasión o desesperanza para justificar nuestros trabajos de urbanismo y fundamentar las virtudes de éstos, no es un engaño; si el viejo concepto y la imagen convenida, que abrigan de manera revuel ta centros históricos, ciudades nuevas, suburbios y megalópolis, no funcionan a la manera de un mito encargado de obviar la impotencia o la angustia, y no disimulan la inadecuación de la palabra y de la cosa. Los historiadores nos han enseñado no obstante, que "los hombres no acostumbran cambiar de vocabulario cada vez que cambian de hábitos"5 y que la permanencia de las palabras contribuye a un periodo de larga duración de nuestros esquemas mentales; es decir, en dado caso, a su anacronismo.

¿No es entonces tiempo de admitir sin remordimientos, la desaparición de la ciudad tradicional y de interrogarse también sobre aquello que la ha remplazado, en breve, sobre la naturaleza de la urbanización y sobre la no ciudad en que parece haber devenido el destino de las sociedades occidentales avanzadas? Tal será mi propósito.

LA PALABRA Y LA COSA

Cuestión previa necesaria a la exploración del campo urbano entre 1850 y 1950, será una rápida digresión concerniente a tres términos: ciudad, urbanismo y técnica. Para los dos primeros se tratará de recordar su acepción original. Para el tercero, por el contrario, se hará un acercamiento - no filológico - que pertenece a los hechos, destinado a poner en evidencia el lazo, reconocido insuficientemente, que liga la técnica a la ciudad y hace de este término una palabra clave del campo urbano.

${ }^{5}$ Fórmula de Marc Bloch, en Bloch, M. (1974) [1945], A pologie pour I'histoire. 7a ed., París: A. Colin, pp. 40-41. 
Ciudad

Se pondrá entre paréntesis su sentido institucional: objeto de una convención, variable según el país (en Francia población aglutinada de al menos dos mil habitantes en una sola comuna, y que constituye un instrumento administrativo, jurídico y fiscal). En el lenguaje común de hoy, la ciudad continúa designando el lugar o soporte estático de una triple comunicación que compromete el intercambio de bienes, de informaciones y de afectos. Ella permanece concebida como la unión indisociable de aquello que los Romanos Ilamaban urbs (territorio físico de la ciudad) y civitas (comunidad de ciudadanos que la habitan), o todavía más como la pertenencia recíproca de una entidad espacial discreta y fija, y de una población.

Pero la entrada en la era industrial y las concentraciones demográficas sin precedente que ésta induce han desgastado esta asociación ancestral. Desde 1855, Haussmann lo subrayaba a propósito de París en un discurso pronunciado ante el consejo municipal: "¿Está bien hablar propiamente como de una 'comuna' de esta inmensa capital? ¿Qué relación municipal une a los dos millones de habitantes que aquí se apretujan? ¿Se pueden acaso observar entre ellos afinidades de origen? ¡N o! La mayor parte pertenece a otros D epartamentos; ${ }^{6}$ muchos a países extranjeros, en los cuales conservan sus parientes, sus más caros intereses y a menudo la mayor parte de su fortuna. París es para ellos como un gran mercado de consumo; un inmenso campo de trabajo; una arena de ambiciones; o solamente una cita de placer. No es su país". ${ }^{7}$

Etimológicamente, la palabra francesa "ville" viene del latín villa. Designando un asentamiento rural autárquico que a menudo constituyó el núcleo de las ciudades medievales. Esta etimología subraya la pertenencia de la ciudad europea preindustrial al campo. Lewis Mumford fue uno de los primeros que nos enseñó que a excepción de

\footnotetext{
${ }^{6}$ Entidad territorial administrativa, equivalente a un estado en la República mexicana. [N ota del traductor].

${ }^{7}$ Haussmann, G. E. (Barón de) (1891), M émoires. Tomo ॥. París-H arvard: p. 199 (reedición crítica: París: Le Seuil, 2000).
} 
algunos centros congestionados, la ciudad medieval no estaba nada más "en el campo, sino que era del campo", 8 y esta relación de interdependencia es hoy vuelta a poner en evidencia por los historiadores de la ciudad europea. ${ }^{9}$ La revolución industrial socavó una asociación original, rompió la relación de complementariedad que unía la ciudad al campo y cavó entre ellas la famosa diferencia que el comunismo, según Marx, debería suprimir. Sin embargo, no es gracias a una revolución social, sino a una permanente evolución técnica que dio inicio la supresión de esta diferencia. Veremos que el proceso prosigue y tiende a eliminar en provecho de una entidad que no es ya ni la ciudad ni el campo, los dos términos, que lógica y fenomenológicamente existían el uno para el otro.

U rbanismo

El término es un neologismo propuesto por el español Ildefonso Cerdá en su "Teoría general de la urbanización" (1867). Este término fue introducido en Francia, en el curso de la década de 1910, por H. Prost y un grupo de practicantes que gravitaban al rededor del Museo Social. La noción de urbanismo nació en el marco de una reflexión sobre el impacto espacial de la revolución industrial: la ciudad padece entonces un trastorno espontáneo que parece surgir de un cataclismo natural incontrolable.

Desde su creación, la palabra ha servido para designar dos procedimientos diferentes. Por una parte, "urbanismo" designa una disciplina nueva que se declara autónoma y quiere ser la ciencia de la concepción de las ciudades. Ella postula la posibilidad de un dominio completo del hecho urbano y ha elaborado con este fin teorías clasificables en dos corrientes: una denominada progresista se enfoca al progreso y a la productividad; la otra denominada cultural ista, se focaliza sobre objetivos humanistas. No obstante, a pesar de sus diferencias, las teorías de ambas corrientes se fundamentan en un procedimiento

\footnotetext{
${ }^{8}$ M umford, L. (1938), The Culture of Cities. Londres: Secker and Warburg, p. 306.

9 Mohenberg, P.M. y Lee, L. M. (1985), The Making of U rban Europe (1000-1950). Cambridge, Mass.: Harvard University Press (traducción francesa: (1991), La formation de l' Europe urbaine. París: Presses Universitaires de France (puF)).
}

162 Andamios 
idéntico: el análisis crítico de la ciudad existente y la elaboración en contracorriente de un modelo de ciudad construible y reproducible ex nihilo.

El modelo progresista (Congresos Internacionales de Arquitectura Moderna (CIAM), Le Corbusier) propone un objeto urbano expandido cuyos componentes estandarizados son repartidos en el espacio según un orden funcional y geométrico. El modelo culturalista (la ciudad jardín de Howard) es por el contrario compacto y multifuncional. El modelo progresista dominó el escenario europeo desde los años 1920, pero no recibió una aplicación significativa sino hasta después de la Segunda Guerra mundial y de la reconstrucción. Fue en la misma época que comenzaron a darse las pretensiones científicas del urbanismo teórico. ${ }^{10}$ "El postulado del espacio objetivo y neutro"11 fue denunciado. La naturaleza política e ideológica del reordenamiento de la ciudad; dicho de otra manera, la selección de valores que forman la trama fue puesta en evidencia: numerosas disciplinas científicas pueden contribuir a la organización del espacio urbano, pero una ciencia normativa de la ciudad es una noción contradictoria. Se ha mostrado que las teorías del urbanismo llegaban a un pensamiento anacrónico, "cosista"12 y marcado en el ámbito de la utopía: la modelación urbana aparece como un dispositivo reductor, el instrumento totalitario de un condicionamiento.

Por otra parte y al mismo tiempo, "urbanismo" designa también otro procedimiento, pragmático y sin pretensión científica, que no se enfoca a cambiar a la sociedad, sino que modestamente busca regularizar y organizar con la mayor eficiencia el crecimiento y el movimiento de los flujos demográficos, así como la mutación de la escala de las construcciones y de los equipamientos inducidos por la revolución industrial.

\footnotetext{
10 Véanse en particular, Argan, G. C. (1957), Architettura e ideología. Milán: Zodiac; Choay, F. (1965), L'U rbanisme, utopies et réalités. París: Le Seuil, y (1980), La règle et le modèle, París: Le Seuil; Lefebvre, H. (1968), Le Droit à la ville. París: Anthropos.

${ }^{11}$ Lefebvre, H. (1970), "Réflexions sur la politique de l'espace" en Espaces et sociétés. Núm. 1, París: p. 3.

${ }^{12}$ Doctrina fil osófica que concibe las ideas y los conceptos como cosas. [N ota del traductor].
} 
Aún antes de la creación de la palabra "urbanismo", el arquetipo de este procedimiento, que sin duda valdría más llamar "reordenamiento regularizador", aparece con los "grandes trabajos" de Haussmann. El verbo "regularizar" vuelve por cierto en muchas ocasiones en las Memorias del ex Prefecto de París, confirmando su papel anticipador y el parentesco de su acercamiento con los "Regulierungspläne" (planos reguladores) de Stübben y de Wagner en Alemania y en Austria, y los planos reguladores de los urbanistas franceses Henard, Prost y Jaussely.

Técnica

El Deus ex machina que jala los hilos del teatro urbano desde el gran cataclismo de mediados del siglo xIx. Sabemos que la ciudad es un fenómeno demasiado complejo para ser pensada en términos de cadenas causales simples: ella pone en juego abanicos de determinaciones, comprometidas, en los giros de retroacción, de los cuales aún el análisis sistémico no puede agotar la complejidad. No obstante, para explicar los trastornos espontáneos o concertados sufridos por la ciudad europea preindustrial, los historiadores han hecho énfasis sobre todo en los factores económicos y políticos (el rol del capitalismo, la lucha de clases), así como en los factores demográficos (crecimiento, masificación, flujos, éstos mismos condicionados por el progreso de la higiene, la epidemiología y por el éxodo rural). El papel jugado por la técnica en la mutación de la ciudad europea ha sido demasiado desconocido como para no privilegiarlo aquí. La reflexión (no filosófica) sobre la técnica y su historia tiende a aislarla en su propio campo, mientras que está simultánea y directamente implicada, al mismo tiempo, en la morfogénesis del espacio urbano y en la génesis de las mentalidades y de los comportamientos urbanos.

Cerdá fue el primero en juzgar este poder haciendo de las técnicas de transporte el motor de la historia espacial de las ciudades, que la invención del ferrocarril y la utilización de la electricidad vinieron a revolucionar.

Para valorar las etapas de la transformación urbana acaecida entre 1870 y 1990, se podría hoy retomar de manera más global la secuencia 
de innovaciones técnicas que inauguran y van marcando este periodo. Entre los campos más significativos están:

- La construcción: Cerdá no menciona este campo cuyo papel había sido señalado en la misma época, primeramente por Viollet-le-Duc y desarrollado más tarde, particularmente por dos historiadores de la arquitectura, Sigfried Gideon ${ }^{13}$ y Reyner Banham. ${ }^{14}$ Recordemos la incorporación progresiva en el curso de la segunda mitad del siglo $x I x$, de los nuevos materiales de construcción (acero, concreto, vidrio), cuyos procedimientos de aplicación contribuyeron a cambiar el estatus de los edificios y a permitir su transformación en objetos técnicos; los equipamientos mecánicos y eléctricos, que permitieron densificar el tejido urbano al generalizar la construcción en altura (ascensor) y de "acondicionar" (aire, temperatura) los edificios, liberándolos de esta manera de un conjunto de limitaciones de implantación y de dimensionamiento; la industrialización de los edificios, que estandariza el marco construido y sirve no solamente al derramamiento periférico de la ciudad, sino a un establecimiento más difuso de la construcción en el territorio entero.

- Los transportes. A partir de 1850, el ferrocarril le dio acceso a la sociedad occidental a una movilidad de masas sin precedente y se convirtió en el más poderoso factor de densificación de las ciudades. Después, a finales del siglo xıx, secundado por el tranvía y el M etro, sirvió también para la expansión de la ciudad. A partir de la década de 1930, el automóvil le regresó a las redes carreteras su papel perdido en las expansiones de la ciudad, y aumentó aún más la movilidad general, en tanto que la aeronáutica contribuiría a fijar los grandes núcleos urbanos.

- Las telecomunicaciones. El telégrafo, la radio, el teléfono con sus últimas aplicaciones informatizadas han sido respectivamente aparejadas con las diferentes técnicas de transporte de las cuales

\footnotetext{
${ }^{13}$ Gideon, S. (1948), M echanization Takes Command. Nueva York: Oxford University Press.

${ }^{14}$ Banham, R. (1949), The architecture of the Well Tempered Environment. Londres: Architectural Press.
} 
controlaban o controlan su funcionamiento. Además, las telecomunicaciones han multiplicado directamente los intercambios de información de los citadinos, extendiendo su campo de acción, transformado su experiencia del espacio, del tiempo y por lo mismo, la estructura de sus comportamientos.

LA ÚLTIMA FIGURA DE LA URBANIDAD

Dela mutación urbana, sobre la cual la exposición del centro Pompidou nos deja ver el ineludible cumplimiento, con fulguraciones, estancamientos y yerros, se imponen algunos puntos centrales. Pero su sucesión se ordena a partir de un origen del cual se lamenta la ausencia en la obra de Haussmann, quién dejó su marca en la mayor parte de las ciudades de Europa.

El París de Haussmann tiene un valor de límite: punto de arribo de una tradición y punto de partida de otra. El lazo de la capital metamorfoseada con la ciudad preindustrial es tanto más fuerte que, por una ironía de la historia, París permanecía entonces en Europa como la única metrópoli cerrada, encerrada al interior del muro anacrónico deseado por Thiers y que cayó sólo hasta la Primera Guerra mundial. Pero a pesar de este encierro, París jugó un papel inaugural gracias a la regularización que le impuso el Prefecto. Por primera vez éste trató al conjunto de los espacios heterogéneos de la capital como una entidad única, a la cual un plan global dotó de isotropía. Este plan que transformó los París de Balzac en la metrópolis de Zola, permitió de manera particular tres logros mayores y solidarios. Hizo de la ciudad entera un sistema de comunicaciones: una red jerarquizada de vías disgrega los barrios, pone en comunicación a los puntos clave y cardinales de la ciudad entre ellos y con las estaciones de ferrocarril, puertas urbanas que conectaban la ciudad cerrada con el conjunto del territorio nacional. Como corolario, también amplió la escala de la ciudad entera, conjugando operaciones quirúrgicas (cortes, excavaciones, ampliaciones) e injertos (integración intramuros de todos los espacios libres tanto en el interior como en el exterior de la barrera "des Fermiers-Géneraux" 
(recaudadores de impuestos del viejo régimen)). En fin, Haussmann dotó a la ciudad entera de un equipamiento higiénico concebido bajo la forma de redes técnicas isomorfas y de un sistema respiratorio de espacios verdes.

Si llamamos urbanidad al ajuste recíproco de una forma de tejido urbano y de una forma de convivencia, se puede, de justa manera, hablar de una urbanidad haussmaniana. Ciertamente, la ampliación de la escala de las vías, de las parcelas y de las construcciones, rompió el marco de las relaciones sociales de proximidad, característico de la ciudad preindustrial. Pero el nuevo marco de una nueva convivialidad lo reemplazó. Por una parte, el tejido urbano de dimensiones agrandadas conservó una continuidad que satisface el ojo y el cuerpo por la proporción recíproca y rigurosa de las dimensiones (ancho y alto) de las vías, banquetas y edificios que los bordean. Sobre todo, una estructura de pequeña escala, encajada en el tejido propiamente dicho, está constituida por un mobiliario urbano diversificado, concebido, diseñado, producido e implantado con cuidado, así como por árboles y cercas de vegetación. Ello hace de las banquetas y de los jardines el teatro de las relaciones sociales inéditas: aleatorias, anónimas y cosmopolitas.

En otros lados, mientras tanto, las fortificaciones habían sido o estaban siendo derruidas. La ciudad (cité) tradicional estallaba bajo la presión demográfica y los fraccionamientos sin fin de los suburbios Iondinenses simbolizaban la expansión salvaje de la ciudad. El ejemplo del París haussmaniano era meditado. Cerdá, Stübben y Wagner lo testimoniaron suficientemente; el procedimiento regulador sería transportado al caso de las ciudades abiertas y según otros procedimientos, éste promovería la misma urbanidad inédita, por ejemplo en Viena y en Barcelona. A diferencia de París, en estos dos casos los antiguos centros históricos fueron dejados más o menos intactos, con pesar por parte de Cerdá; y por parte de 0 tto Wagner con la voluntad explícita de preservar el pasado. "Conviene aquí respetar la belleza y satisfacer las exigencias de salubridad y de circulación por medio de una conservación adecuada del patrimonio existente, procurando aportar las mejoras propias que satisfagan las exigencias 
modernas", anotaba Wagner en 1893 en la introducción de su Proyecto de plan regulador para la ciudad de Viena. ${ }^{15}$

Este plan procedía, como el de Haussmann de una visión global y prospectiva de la ciudad. Pero en esta ocasión estaba abierto ampliamente sobre el territorio circundante, a partir del Ring monumental que había sido establecido sobre el trazo de las antiguas murallas. En su versión terminada en 1910, la expansión de la ciudad era controlada por medio de tres instrumentos: un sistema vial indefinidamente prolongable, concebido bajo la forma de anillos periféricos concéntricos, ligados entre ellos y al anillo inicial del Ring por radiales; un sistema de unidades de aglomeración (Stellen, de cien a ciento cincuenta mil habitantes), bien individualizadas, implantables sobre las vías radiales y destinadas a canalizar la urbanización; abundantes reservas de tierras periféricas justificadas por la imposibilidad de una prospectiva urbana. O puesto a toda actitud utópica de la cual recusa el dogmatismo cientificista y la lógica de un objeto discreto, Wagner constata que "no es posible prefigurar con certeza lo que será la imagen de la ciudad futura, dado que un catecismo de lo urbano no existe" ${ }^{16}$ Su plan estaba abierto a los cambios y a las incertidumbres. Pero, tanto en el tratamiento del Ring como en el correspondiente a los Stellen, permaneció apegado a una concepción de la ciudad como un objeto discreto, de tejido continuo. Y si éste tejido no escapaba casi nunca a la desmesura y presentaba lagunas al gunas veces, Wagner se apegaba a paliar este defecto mediante la escala pequeña y la estética acusada de un sistema de amenidades urbanas y mobiliarios urbanos comparables a los de París.

En Barcelona, Cerdá había propuesto una solución a la vez más innovadora y más limitante. Su plan de 1859 (en parte traicionado en su realización) ponía en relación el centro histórico, por fin liberado de sus fortificaciones, con un territorio virtualmente ensanchado a Europa entera. "Los caracteres distintivos de la nueva civilización son el movimiento y la comunicación", y a sus ojos "la ciudad no es sino una especie de estación o de pivote de la gran viabilidad universal". Se

${ }^{15}$ Citado por Trévisiol, R. (1990), Otto Wagner. Roma-Bari: Laterza, p. 182 (traducción deF. Choay). Esta introducción presenta con un avance de dos años las ideas de M oderne Architektur (1896).

${ }^{16}$ Ibíd. p. 182

168 Andamios 
trataba entonces de un plan de extensión indefinida que rompía a la vez con la noción de aglomeración discreta y con los esquemas de organización concéntrica. Estaba fundado en la interconexión de dos redes ortogonales de escala diferente: rejilla mayor, atravesada por diagonales y destinada a un gran tráfico territorial con sus vías de 20 a 50 metros de ancho; rejilla menor, destinada a un pequeño tráfico local y en donde hay manzanas de 133 metros de lado, con un "pan coupé" y el corazón de manzana abierto, constituyendo esto el elemento urbano de base, una especie de unidad de vida y de vecindad.

¿Es pertinente considerar el plan de Cerdá como una de las tres figuras clave del urbanismo de regularización? Varios argumentos parecerían oponerse a esto. Primero, Cerdá fue el primer teórico del urbanismo, del cual pretendía hacer una disciplina científica en todos sentidos. Enseguida, su plan intitulado Reforma y ensanche de Barcelona, efectivamente había sido concebido como el instrumento de una política igualitaria que debería procurar las mismas ventajas a todas las clases de la población, y lleva la marca indiscutible de la utopía. Finalmente, este plan no se contentaba con crear redes de ligas con el territorio, deviene territorio y por lo mismo, parece contradecir la lógica del urbanismo modelador, así como la del urbanismo regularizador. Estas objeciones son no obstante refutables una a una. El plan de Barcelona precedió en cuatro años a la gran obra teórica que constituía una justificación a posteriori. Además, el plan no proponía el modelo de una ciudad nueva, sino estructuras generativas que permitiesen adaptar la antigua ciudad a las técnicas nuevas. Estas estructuras eran deducidas de un doble análisis de la situación específica de Barcelona y de los componentes de la ciudad en general, lo que hace de Cerdá el creador de la geomorfología urbana. Es más, si la capital catalana era convidada a expandirse por todos lados en donde las condiciones físicas lo permitiesen, este proceso estaba controlado por el dispositivo de una doble malla: ésta aseguraba la continuidad (por más ligera que fuera) y la homogeneidad de una trama construida en donde los manzanos normandos ofrecían una entera libertad a la creación arquitectónica y sobre todo, devenían, gracias a la articulación de su pequeña escala con el gran sistema vial, en teatro de una convivencia inédita. Es 
exactamente por esto que el plan de Cerdá debe ser clasificado en la misma categoría que el de Haussmann y de Wagner.

Otros planes cercanos o derivados de estas tres estructuras regularizadoras han asegurado, en otras grandes ciudades o capitales, la permanencia de la urbanidad metropolitana nacida en la segunda mitad del siglo xIx. Hasta mediados del siglo xx todas esas ciudades y muchas más acogieron e integraron, sin por ello ser alteradas, la sucesión y la diversidad de experiencias y estilos arquitectónicos nuevos. El modern style (más barroco en Barcelona, más pictórico en Praga, Viena o Munich, más reservado en París o Bruselas), el clasicismo estructural de Perret, el funcionalismo del CIAM o también el monumentalismo de la arquitectura llamada total itaria, en I talia o en Alemania, añadieron a la ciudad europea un toque plástico nuevo y no modificaron con esto su estructura.

Después de la Segunda Guerra mundial, la reconstrucción es a menudo respetuosa del perímetro de las ciudades destruidas, limitándose a ampliar y homogeneizar su tejido. Le Havre reedificada de arriba a abajo en concreto por Perret, permanece como una ciudad tradicional, fechada solamente por un material y un estilo arquitectónico; junto al tipo metropolitano, el de la ciudad y de la urbanidad preindustriales no había desaparecido en Europa. Numerosos asentamientos antiguos vegetaban y en otros casos, por ejemplo en Italia del norte, Alemania del sur 0 en los M idlands de Inglaterra, la densidad de la armadura urbana antigua limitaba la extensión de las ciudades.

\section{SIGNOS DE DECONSTRUCCIÓN}

Desde el inicio del siglo xx, sin embargo, no habían faltado los signos anunciadores de una deconstrucción inminente de la ciudad europea. Podemos hacer un recuento rápido sin separar los innumerables proyectos, sueños y teorías del pequeño número de las realizaciones. 
La ciudad lineal

En 1882, un intelectual español, Soria y Mata, publicó en el diario madrileño El Progreso un primer proyecto de ciudad lineal, ${ }^{17}$ salido de su reflexión sobre las nuevas técnicas de transporte, telecomunicaciones y sobre las incidencias sociales. Como Cerdá, él estaba convencido de que la comunicación bajo todas las formas era el futuro del mundo y como él, se preocupaba por mejorar las condiciones de vida de la clase obrera. Pero en lugar de pensar el proceso de comunicación generalizado que es la urbanización en términos de expansión homogénea y multidireccional, él lo concebía bajo la forma puramente lineal: "Una calle indefinidamente extensible de 500 metros de ancho".

El eje longitudinal de la ciudad lineal reagrupa las vías de transporte (ferrocarril, tranvía, carreteras) las redes técnicas de distribución de gas, agua, electricidad, teléfono, así como los servicios municipales y los parques. De un lado y de otro de esta espina dorsal, dos bandas Iongitudinales formadas de manzanas ortogonales asocian el hábitat individual a los edificios públicos, comerciales, culturales y se desarrollan más o menos en función de las necesidades. Este modelo estaba destinado a suprimir la concentración y la densificación urbana; debía evitar la diseminación de la construcción a través del territorio y preservar la integridad del campo. Finalmente, simplificaba al máximo la interconexión de las redes técnicas.

Soria imaginaba así una "ciudad lineal" ininterrumpida de Cádiz a San Petersburgo, estableciendo por primera vez el problema de los asentamientos humanos a escala mundial. Pero las ambiciones de Soria eran prematuras y no pudo aplicar su modelo más que en las dimensiones de un suburbio de Madrid accesible a través de una vía central de tranvía.

El mismo esquema de desarrollo fue retomado a finales de la década de 1920 en la Unión Soviética por un grupo de arquitectos eingenieros. El asentamiento lineal significaba para ellos la abolición de la ciudad y

${ }^{17}$ Lo desarrolló enseguida en numerosos artículos y en la revista Ciudad lineal que él fundó en 1896. Véase también: Collins, G. R. (1959), "Linear Planning throughout the World", en Journal of theSociety of Architectural Historians, núm. xvIII, octubre. Philadelphia. 
se designaban ellos mismos como "desurbanistas". Ellos conocían las publicaciones de Soria y es probable que se hayan inspirado de ellas. Pero su modelo, más elaborado, de un "zoning" (zonificación) riguroso, servía para objetivos diferentes: la realización del socialismo y la optimización de la producción industrial: como N. Milioutine lo mostraba en un libro teórico importante, ${ }^{18}$ la cadena de producción era transferida de la fábrica a la escala del territorio. El proyecto "desurbanista" recibió un principio de aplicación en la ciudad de Magnitogorsk (realizada por Iván Leonidov en 1929) y en Stalingrado (Milioutine, 1930). Pero en 1931, Stalin le puso punto final a estas "desviaciones" ideológicas.

Los Congresos Internacionales de Arquitectura Moderna (CIAM): ciudad máquina y desaparición de la urbanidad

Le Corbusier se burló de los "desurbanistas" en nombre de la defensa de la ciudad; pero la utopía que él describió y que diseñó durante su vida con el nombre de ville radieuse ${ }^{19}$ (ciudad radiante) ¿era realmente una ciudad? Su idea se presenta más bien como la deconstrucción sistemática de todos los tipos de ciudades anteriores, de toda forma de aglomeración continua y articulada. Y es en lo que queda, el mismo tipo de desintegración y el mismo modelo que desde 1920 a 1950, incasablemente proponen los planes de Le Corbusier para París, Argel, Saint-Dié, Albi...

La "ville radieuse" me servirá de paradigma para definir - esquemáticamente- el urbanismo de los CIAM, donde Le Corbusier fue el instigador en 1928 y luego uno de los principales protagonistas. Esta elección es legítima, puesto que si Le Corbusier poco inventó en la materia, "su gran mérito" según palabras de Bruno Taut, "es la puesta en forma literaria de los principios modernos". Él ejerció una

\footnotetext{
${ }^{18}$ Milioutine, N. (1930), Sostgorog, Leningrado, traducido al inglés (1974) con notas y comentarios de G. R. Collins y W. Allix, Cambridge: mıт Press (traducción francesa (2002) por E. Essaïah, Sotsgor od. Le problème de la construction des villes socialistes, presentado por J. L. Cohen, Besançon: Editions de L'imprimeur).

${ }^{19}$ Le Corbusier (1933), La ville radieuse. París: Vincent Fréal.
}

172 Andamios 
influencia internacional sin igual, respecto al reordenamiento urbano y del territorio después de la Segunda Guerra mundial.

CIAM

El congreso representó, en intervalos regulares, un momento culminante de militancia y de formulación doctrinal para los miembros de un movimiento que agrupaba arquitectos reunidos por su voluntad de romper con el pasado y por su fe en la técnica. Este movimiento surgió de la crisis abierta en el curso de la segunda mitad del siglo xıx por la transformación de las técnicas de construcción, y la amenaza que hizo pesar sobre el estatus de los arquitectos. Este movimiento respondía, a su manera, a la puesta en guardia de Emile Viollet-le-Duc, que temía, al término de sus Entretiens (conversaciones), que "los arquitectos [hayan] terminado su papel [y que] el de los ingenieros comience". ${ }^{20}$

Los miembros del cIAm redefinieron entonces el papel del arquitecto en una nueva sociedad tecnicista, en donde ellos reivindicaban el reordenamiento global. Pero romper sin opción alguna con su propia tradición y asimilar la amplitud y el alcance de los trastornos técnicos acaecidos en su campo, hubiera exigido de su parte la adquisición de nuevos saberes y nuevas capacidades. Ellos se ahorraron casi siempre esta adquisición privilegiando una ideología de vanguardia. Combatían por una causa: la modernidad. Luchaban para erradicar las formas y las tradiciones arquitectónicas del pasado. La modernidad estaba simbolizada para ellos por objetos (silos, paquebotes o navíos de carga) más que por procesos y nuevos sistemas de relaciones. El edificio estaba pensado como objeto técnico, incluso como máquina, de lo cual atestigua la famosa fórmula de "máquina para habitar" tomada prestada a Ozenfant por Le Corbusier.

Corolarios: el edificio se convertía en objeto autónomo, desligado de cualquier dependencia o articulación contextual y en su caso, susceptible de ser reproducido por la industria. Más aún, este nuevo estatus del

${ }^{20}$ Viollet-le-Duc, E. E. (1872), Entretiens sur l'architecture, tomo II. París: Morel \& Co., p. 445. 
objeto arquitectónico contaminaba el de la ciudad, el cual habiendo enarbolado los mismos principios, pasaba a estar bajo el control del arquitecto; transferencia de competencias avalada por la Carta de Atenas ${ }^{21}$ que elaboró el CIAm en 1933. La ciudad se transformaba a su vez en máquina de vivir y debía, ésta también, hacer "tabla rasa del pasado". Se excluía la conservación de los centros antiguos como núcleos dinamizantes de un nuevo desarrollo, según el procedimiento del urbanismo regularizador: el "Plan Voisin" de París ${ }^{22}$ era ejemplar, pues arrasaba los barrios antiguos y no conservaba sino algunos monumentos aislados que devenían curiosidades históricas y turísticas. Le Corbusier proscribió de la "ville radieuse", a la calle que articulaba los elementos del tejido urbano, generaba lo compacto de las ciudades antiguas y devenía de esta manera responsable de su insalubridad y de su "desorden". La "ville radieuse" higiénica y ordenada, era ubicada bajo el signo de la función; ella reducía la vida urbana a cuatro tipos de actividades: el hábitat, el trabajo, la circulación y el esparcimiento. Las dos primeras estaban alojadas en "unidades" gigantes, autónomas, cuyos diferentes tipos se estandarizaban; la tercera era concebida como un sistema jerarquizado de caminos (elevados o en segmentos) que aseguraban, gracias al automóvil, la interrelación de las megaestructuras y su liga con el territorio; la cuarta parecía desarrollase en el espacio verde indiferenciado donde "cien por ciento del suelo pertenece al peatón". 23

Conjunto discontinuo de megaestructuras clasificadas en subconjuntos discontinuos: la red carretera ofrece la única continuidad entre los grandes equipamientos integrados en una configuración geométrica simple, legible solamente en el plano o vista aérea. La comunicación

${ }^{21}$ Documento colectivo cuya versión original fue publicada en francés y en holandés en 1933. Una versión comentada fue publicada por Le Corbusier en 1943, y fue reeditada, desafortunadamente sin notas explicativas, como libro de bolsillo: (1971), La Charte d'Athènes, París: Le Seuil (colección Points-Architecture).

22 Propuesto en 1925 por Le Corbusier, quien le puso el nombre del constructor de automóviles Gabriel Voisin.

${ }^{23}$ Le Corbusier, La ville radieuse, op. cit., fórmula que se repite, de un extremo al otro del libro.

174 Andamios 
se resuelve en circulación, la escala local y la urbanidad dejan su lugar a la única escala territorial.

Este modelo inspiró la renovación urbana y los grandes conjuntos después de la Segunda Guerra mundial: pero bajo una fraseología modernista, su deconstrucción radical de la ciudad no es menos anacrónica. Esta recoge un fijismo (o estado de inmovilidad) utópico puesto al servicio de una visión paleotécnica, en las antípodas de un pensamiento de la complejidad.

El privilegio exclusivo acordado a la escala territorial por el Movimiento Moderno tiene sin embargo una excepción que concierne a ciertos programas municipales de ciudades obreras. En el sentido directo de una tradición inaugurada a finales del siglo xIx por los patrones de la industria en la Gran Bretaña y en Alemania, un puñado de arquitectos supo concebir y realizar en la periferia urbana para las poblaciones obreras o de ingresos modestos, las pequeñas ciudades cuya escala, articulación espacial y el tratamiento sofisticado de materiales, poco onerosos, indiferentemente modernos o tradicionales, hacían verdaderos núcleos de vida social. Las realizaciones de Bruno Taut, ejemplares aún hoy, donde se les estudia y se les restaura (por ejemplo, en los suburbios de Berlín), traducen la búsqueda de un contrapunto local frente al proceso, plenamente asumido, del Auflösung der Städte $e^{24} \mathrm{o}$ la desintegración de las ciudades.

\section{La "garden-city" entre dos mundos}

Ya no más contrapunto sino contraposición, la ciudad jardín de Ebenezer Howard, era situada por Le Corbusier exactamente al lado opuesto de su "ville radieuse". Su valor sintomático no residía en una participación, simbólica o concreta, en el proceso de desagregación de la ciudad europea, sino en la reacción antagónica que ésta le oponía. A la amenaza de deconstrucción que ilustraba el estallido difuso de Londres en su suburbio 0 el desarrollo monofuncional de las ciudades del Black Country, ella respondía con un proyecto de reconstrucción.

${ }^{24}$ Taut, B. (1920), Die Auflösung der Städte. Hagen: Volkwaang Verlag. 
No hay que confundir esta ciudad-jardín con la "cité-jardin" francesa, que es una ciudad dormitorio más o menos lograda según el caso. La garden-city que proponía Howard en su libro Tomorrow: a Paceful Path to Social Reform (1898) ${ }^{25}$ era un modelo de ciudad completo y suponía un proyecto de sociedad global. Su inventor era un reformador social. Él no diseñó su propuesta sino que la presentó bajo la forma abstracta de un esquema o "diagrama", cuyo objetivo era repartir racional mente y fijar armoniosamente los flujos demográficos y las actividades sociales en las aglomeraciones discretas, de pequeñas dimensiones, y casi autárquicas, que no debían exceder los treinta mil habitantes; circunscritas por amplios cinturones verdes, reagrupaban concéntricamente todo tipo de instituciones y actividades sociales. Los sectores industrial y agrícola estaban localizados en la periferia, pero en el interior de la entidad física definida por la corona verde. Una red ferroviaria unía estas ciudades entre sí; las hacía constituir un conjunto de sistemas interconectados y gravitando cada uno al rededor de una ciudad central de sesenta mil habitantes.

El dispositivo tenía por objeto preservar a la vez la ciudad y el campo y poner su complementariedad al servicio de la urbanidad y de la calidad de vida previniendo la diseminación de las construcciones, percibida como un al to riesgo social y cultural. Esto permitía también operar una apacible revolución social gracias a un complejo conjunto de mecanismos financieros y sobre la tenencia de la tierra, cuya descripción rebasa mi propósito.

El esquema de Howard no deja de tener un parentesco con aquel de Soria y Mata, la utilización del ferrocarril lo inserta bien en la lógica del desarrollo técnico. Pero siempre racionalizando el reparto del territorio, produce el modelo fijo y discreto de la ciudad preindustrial. De un modo sistemático, regresa igualmente - su nombre lo indica- a la ruralidad de la ciudad medieval.

Inglaterra, país que ha sabido siempre aliar innovación y tradición, reserva una acogida entusiasta a Tomorrow. La primera "garden city", se

25 (1898), Londres: Swann Sonnenschein. En la segunda edición en 1902, el título deviene Garden-Cities of Tomorrow.

176 Andamios

Volumen 6, número 11, agosto, 2009, pp. 129-148 
empezó a construir en 1930 en Letchworth y el modelo de Howard debía continuar inspirando la creación de New Towns ingleses después de la Segunda Guerra Mundial. Sin embargo, en ningún caso el esquema howardiano pudo ser seguido al pie de la letra. Este desfase y las disfuncionalidades que no pudo evitar, tiuvieron como consecuencia la proyección anacrónica de la ciudad preindustrial que neutralizó las innovaciones de la "garden city".

Una anticipación realista

El retroceder en la historia nos permite hoy leer la escala territorial de la "ville radieuse" y la rehabilitación de pequeñas escalas de reordenamiento local realizadas por Howard, como los signos de una próxima deconstrucción de la ciudad europea. No obstante, sin la ayuda de la perspectiva histórica, sin el apoyo del procedimiento utópico y fuera del marco de la ciencia ficción, los índices de esta deconstrucción fueron descritos y las consecuencias de éstos analizadas, ${ }^{26}$ y aplicadas en la época, por un espíritu cuya clarividencia ha sido mal reconocida, ${ }^{27}$ el italiano Gustavo Giovannoni (1873-1943). Su lucidez se debe, sin duda, a una triple formación de ingeniero, arquitecto e historiador del arte. Esta múltiple pertenencia disciplinaria le permitía, en efecto, no focalizar su atención sobre una escala única de reordenamiento, darle un papel inédito al patrimonio urbano antiguo y formular un conjunto de hipótesis que pueden todavía hoy guiar la reflexión sobre la forma de los asentamientos humanos en las sociedades avanzadas. El ingeniero Giovannoni había comprendido que las grandes redes de comunicaciones y de telecomunicaciones concebidas a la escala de territorios devenían en canal obligado de la urbanización y el instrumento de su diseminación. Como técnico competente, él presentía la complejidad

\footnotetext{
${ }^{26}$ Giovannoni, G. (1913), "Vecchie città ed edilizia nuova”, en Nuova Antologia, núm. 995, Milán. El mismo título es retomado para un voluminoso libro (1931), Vecchie città ed edilizia nuova. Turín: UTET (traducción francesa: (1998), La ville ancienne face à I'urbanisme. París: Seuil).

${ }^{27}$ Por los ataques contra él o el silencio deliberado de los historiadores italianos de la arquitectura después de la Segunda Guerra mundial. La rehabilitación de Giovannoni es reciente.
} 
virtual de estas redes, desconocidas por los ciam. Veía en ella, el instrumento de una des-densificación de las ciudades, de su reducción por lo que él llamaba un proceso de "anti-urbanización", privilegiando una distribución más flexible y menos densa de aglomeraciones más pequeñas.

Como arquitecto, Giovannoni estimaba no obstante que si las grandes redes técnicas de equipamiento son necesarias para el desarrollo de la nueva sociedad, estas no son suficientes: necesitan la conexión de un complemento igualmente necesario y no suficiente, de lugares de estancia y reposo cuya estructura surge esta vez de una práctica arquitectónica. Dicho de otra manera, el marco espacial de la nueva sociedad entabla una dial éctica entre dos escalas de reordenamiento, una territorial y otra local. Pero, ila forma y las dimensiones de los lugares de estancia, de los asentamientos de la cotidianidad, se confunden con aquellas correspondientes a las ciudades preindustriales? Para Giovannoni el conjunto del patrimonio urbano existente sería sin duda utilizable para este fin, fragmentariamente y bajo la reserva de un tratamiento conveniente. Pero la flexibilidad de implantación y de dimensionamiento que permite la infraestructura reticular no dejará de suscitar la creación de nuevas tipologías.

Como historiador del arte y lector de Camilo Sitte, Giovannoni desarrolla en particular tres tesis: 1. El espacio urbanizado le corresponde a dos estéticas distintas, de las cuales una implica al ingeniero y la otra al arquitecto; 2. El estudio del tejido de los centros urbanos históricos revela una escala de proximidad que puede servir como principio generador y regulador en la concepción de nuevos tipos de asentamientos, y 3. El patrimonio urbano antiguo no debe ser relegado a las funciones museísticas; este puede en efecto desempeñar un importante papel en la ciudad, pero a condición de que su nuevo destino sea compatible con su morfología, ser utilizado en usos contemporáneos, de proximidad y por lo tanto integrados en los planes urbanísticos y de reordenamiento. Giovannoni, practicante, se ciñe a esto en Italia. 
LO URBANO CONTRA LA CIUDAD: CULMINACIÓN DE UNA MUTACIÓN.

La concomitancia y la sinergia de un conjunto de innovaciones técnicas abren, a partir de 1960, una fase crucial en el proceso de urbanización de Europa: el establecimiento de las condiciones necesarias para que finalice la mutación empezada un siglo antes.

Entre estas innovaciones, las más determinantes conciernen primero a los transportes y la comunicación a distancia. Las redes de transporte del Tren a Gran Velocidad (TGV) y del Metro a gran velocidad; los grandes cargueros que multiplican la velocidad y la capacidad de las redes aéreas; Ias nuevas aplicaciones del teléfono con la consulta a distancia de datos informatizad os y la transmisión inmediata de mensajes escritos: todos estos instrumentos confieren a quienes los utilizan un tipo de ubicuidad.

\section{El espacio sojuzgado por la velocidad}

La reducción de la duración en los desplazamientos, así como en la adquisición y la comunicación de la información abolieron una parte de las antiguas limitantes y servidumbres espaciales a las cuales estaban sometidos los asentamientos humanos. Las nuevas velocidades de circulación favorecen de idéntica manera dos tipos opuestos de movimientos y de implantaciones.

Por una parte, una tendencia a la concentración focaliza los flujos humanos en dirección de polos de atracción que continúan siendo las metrópolis nacionales o regionales; pero las actividades se implantan en las periferias siempre más ampliamente irradiadas, cuya expansión, ligada a la saturación progresiva de las redes técnicas, coincide con el despoblamiento general y progresivo de los centros y de los núcleos urbanos históricos.

Por otra parte, una tendencia a la dispersión opera una desconcentración lineal, o bien puntual. Ejemplo del primer caso es la urbanización que continúa bordeando las costas o valles fluviales. Como ejemplo del segundo caso se tienen las aglomeraciones alojadas alrededor de las terminales aéreas (aerociudades) o de centros de investigación y de universidades (tecnopolos), las mega-máquinas 
comerciales o culturales, que no son imputables a la influencia de los Estados Unidos de América, sino que son la consecuencia inevitable de una lógica de equipamiento técnico; en fin, la implantación difusa de hábitat en zonas rurales que ha recibido el nombre de rurbanización. ${ }^{28}$ Sucede también que todos estos tipos de implantación están asociados: el sueño lineal de Soria y Mata se realiza hoy, entre Génova y Marsella, pero surtido de desbordamientos laterales, densos o diseminados, que por otro lado han destruido irremediablemente antiguos asentamientos y paisajes ancestrales.

En otras palabras, la era de las entidades urbanas discretas se terminó. La era de la "comunicabilidad universal" anunciada por Cerdá y Giovannoni es también aquella de la urbanización universal, difusa y explosiva. Ingenieros, ${ }^{29}$ geógrafos, ${ }^{30}$ y demógrafos ${ }^{31}$ se ponen de acuerdo o coinciden en que el modelo llamado de "lugar central", con el cual W. Christaller ${ }^{32}$ explicaba el crecimiento y la repartición de las ciudades, ya no puede dar cuenta de una estructuración generalizada, a la vez más estable y sobre todo menos centrada, así como de escurrimientos de urbanización en forma de filamentos y de tentáculos caprichosos que ponen en evidencia las nuevas técnicas de cartografía. Toda vez que si, según palabras de Herve Le Bras, "el pasaje de una geografía de polos a una geografía de líneas significa la modernización",33 no existe modelo aún que alumbre la fluctuación y las incertidumbres inherentes a los nuevos estilos de poblamiento.

\footnotetext{
${ }^{28}$ Bauer G. y J. M. Roux (1976), La rurbanisation. París: Le Seuil.

${ }^{29}$ Por ejemplo, Dupuy, G. (1991), Systèmes, réseaux et territoires. París: Presses de l'Ecole nationale de ponts et Chaussées; Veltz, P. (1992), "Hiérarchie et réseaux dans I'organisation de la production et du territoire", en A. Liepitz y G. Benko, Les Régions qui gagnent. Districts et réseaux les nouveaux paradigmes de la géographie économique. París: PuF. ${ }^{30}$ Georges, P. (1989), Les hommes sur la terre: la géographie en mouvement. París: Seghers. Véanse también los trabajos de Th. Saint-Julien y D. Pumain.

${ }^{31}$ Le Bras, H. (1993), De la planète au village. París: Datar-Editions de L'Aube.

${ }^{32}$ Christaller, W. (1933), Die zentrallen Orten in Süd Deuchtland. Jena: G. Fisher.

${ }^{33}$ Le Bras, H. (1993), De la planète au village, op. cit. p.146.
} 
Divorcio entre urbs y civitas

La dinámica de las redes técnicas tiende a sustituirse de esta manera a la estática de los lugares construidos para condicionar mentalidades y comportamientos urbanos.

Un sistema de referencias, físico y mental, constituido por redes materiales e inmateriales así como por objetos técnicos, cuya manipulación pone en juego un capital de imágenes y de informaciones, repercute en un circuito cerrado en las relaciones que nuestras sociedades mantienen con el espacio, el tiempo y los hombres. ${ }^{34}$ Este sistema operativo válido y desarrollable en todo lugar, en las ciudades como en el campo, en los pueblos como en los suburbios puede ser llamado lo urbano.

El advenimiento de lo urbano deshace la antigua solidaridad entre urbs y civitas. La interacción de los individuos es de ahora en adelante, a la vez, desmultiplicada y deslocalizada. La pertenencia a comunidades de intereses diversos no se funda ya ni sobre la proximidad ni sobre la densidad demográfica local. Transportes y telecomunicaciones nos implican en relaciones cada vez más numerosas y diversas, miembros de colectividades abstractas 0 en las que las implantaciones espaciales no coinciden ya y no representan ya una estabilidad en su duración.

El economista estadounidense Melvin Webber ha sabido calificar con una formula lapidaria - "the nonplace urban realm" (el ámbito sin lugar de lo urbano) $)^{35}$ - la deslocalización de la ancestral civitas, así como analizar ejemplarmente sus repercusiones posibles y explotables, particularmente el teletrabajo que la DATAR ${ }^{36}$ descubre hoy en Francia. Desde 1968, Webber proponía el concepto de "post-city age", ${ }^{37}$ la "era post-ciudad" que resulta ambiguo traducir por "era post urbana", ${ }^{38}$ a

${ }^{34}$ Gras, A. (1993), Grandeur et dépendance. Sociologie des macrosystèmes techniques. París:PuF. ${ }^{35}$ Extraído del título de su artículo: "The U rban Place and the N on place Urban Realm", en Webber, M. (ed.) (1964), Explorations into U rban Structure. Philadel phia: University of Pennsylvania Press.

${ }^{36}$ Delegación para el Reordenamiento del Territorio y para la Acción Regional. [Nota del traductor].

${ }^{37}$ Webber, M. (1968), "The post-City Age", en Daedalus, otoño. New York: American Academy of Arts and Sciences, pp. 1091-1110.

${ }^{38}$ Como me tocó hacerlo varias veces, particularmente en Choay (1992), O rizzonte del posturbano. Roma: Officina. 
partir del momento que se conviene en designar por "urbano" la nueva cultura planetaria y su modo a la vez único y polimorfo de utilizar el espacio habitable.

El examen del léxico administrativo y de sus neologismos descubre la hegemonía de lo urbano: región urbana, ${ }^{39}$ comunidad urbana, distrito urbano... Estas nuevas entidades hablan mucho de la desaparición de la ciudad y el anacronismo de "comuna", "pueblo", "ciudad", tantos términos que muy pronto no llevarán más que a la historia 0 a nostal gias cargadas de sentido. Dado que estas palabras en desuso nos recuerdan también la inevitable realidad de nuestra condición natural animal, el hecho de que cualquiera que sea la inmaterialidad, la abstracción, la multiplicidad de relaciones que los urbanos mantengan entre ellos a través del planeta, ellos están, nosotros estamos, a pesar de nosotros, arrojados al espacio y constreñidos a vivir en él y a permanecer en una parte de él. Pero ¿dónde y cómo?

Pensar lo urbano

Pensar lo urbano es hoy una necesidad. La persistencia de la imagen de la ciudad que lo anula surge de mecanismos de defensa: se niega una realidad demasiado difícil o demasiado desagradable de afrontar. Por ejemplo: un semanario parisino ${ }^{40}$ publicó bajo la forma de un cuento una proyección realista de las posibilidades de deslocalización que ofrecen las redes técnicas; los representantes electos de la población que fueron consultados condenaron de manera unánime esta fantasía en nombre de la perennidad de la ciudad. Pero el mecanismo general recubre los modos de resistencia específicos, que emanan en particular de los medios profesionales.

Viene en primer lugar la persistencia de un urbanismo cosista, empantanado en un acercamiento fijista del reordenamiento. Melvin Webber invocaría la "obsession of placeness" (obsesión por la

${ }^{39}$ Véase Gottmann, J. (1961), M egalopolis. N ew York: Twentieth Century Fund.

${ }^{40}$ Le Point, 5 de junio de 1993. 
ubicabilidad). ${ }^{41}$ La actitud está ilustrada por las utopías pseudotécnicas (Y. Friedman, N. Schöffer, P. M aymont) que florecieron entre el final de la década de 1950 y el final de la década de 1960. Los contradicen, más o menos únicos en su género, los ejercicios del grupo inglés Archigram, fundado en 1961. P. Cook y un puñado de jóvenes arquitectos británicos emprendieron una gran depuración epistemológica. Ellos llaman en su auxilio a la cibernética y a la informática, pero también a los datos de la economía y de la demografía, así como a la cultura pop, para presentar en tiras cómicas las configuraciones ${ }^{42}$ inmediatamente conectables y desconectables sobre las redes técnicas complejas. Ubicuidad, movilidad, reversibilidad, instantaneidad, precariedad, indeterminismo son sus conceptos operativos.

La crítica a los arcaísmos mentales ligados a la ciudad lleva aun más lejos cuando Reyner Banham lanza, siguiendo la huella de Archigram, la propedéutica provocadora del "non-plan of a non city":43 el urbanismo frena los procesos innovadores y espontáneos y el advenimiento de lo urbano en lugar de dinamizarlos. Pruebas retrospectivas de esta afirmación son la ausencia total de impacto de Archigram en la planificación de la época y sobre todo, los proyectos contemporáneos, muy pronto realizados; las ciudades nuevas de las cuales la de Vaudreuil, en Francia simboliza cuanto más el anacronismo.

El acercamiento "fijista" de los desarrolladores estuvo animado por la contribución de ciertas "ciencias sociales" en el marco de la pluridisciplinariedad, entronizada en la época, tanto en la investigación como en el dominio operativo, para paliar las carencias teóricas del urbanismo. Así, por ejemplo la sociología urbana apoyada por las investigaciones de la antropología cultural, pudo con justeza poner en evidencia los lazos de dependencia que, en las sociedades tradicionales, unen el funcionamiento de las instituciones sociales con la morfología espacial. Los trabajos de Claude Lévi-Strauss acerca de la organización

\footnotetext{
${ }^{41}$ Webber, M., Explorations into U rban Structure, op. cit., p. 147.

${ }^{42}$ Véanse (1964-1966), Plug-in-City y (1968-1971), Instant City, en (1972), Archigram. Londres: Studio Vista.

${ }^{43}$ Banham, R., Barker, P., Price, C., Hall, P. (1969), "N on-Plan; Experiment in Freedom", en N ew Society, núm. 26, Londres: pp. 435-443.
} 
espacial de las sociedades homeostáticas, los de Pierre Bourdieu sobre los pueblos kabiles, o lo mismo ciertos análisis concernientes a la estructura de las Medinas (centros de las ciudades árabes), fueron ricos en enseñanzas y susceptibles de tener aplicaciones a la escala de barrios o de manzanas, en el caso de las minorías - económicas 0 culturales- que no se habían integrado a la cultura urbana dominante.

Pero estos datos no podían ser legítimamente transpuestos a la sociedad global, en cuyo seno las nociones de arraigo y pertenencia local han perdido su pertinencia y demandan ser repensadas en función de nuevos parámetros y según una relación inédita con la temporalidad. I gualmente, la historia (de las formas urbanas), tan esclarecedora para comprender el pasado y tratar los tejidos antiguos, sirvió de garantía al historicismo lúdico de los practicantes amateurs y legitimó la proyección de los modelos caducos (L. y R. Krier, Ch. Moore).

Pero la resistencia de la imagen de la ciudad discreta está ligada también a la persistencia de otra imagen y de otra ilusión, aquella de la arquitectura eterna. En efecto, la tendencia aportada por los cIAm se ha confirmado. La arquitectura que ocupa hoy los medios de comunicación cambió de estatus y ésta no tiene ya una vocación local. Esta obedece a una lógica del objeto autónomo y pertenece a la competencia del ingeniero: pero, si la prensa transformó los Foster y los Nouvel en vedettes dela arquitectura, ¿quién entre el gran público conoce el nombre de Ove Arrup? El ingeniero es sin embargo el mago cuyo saber permite las proezas deslumbrantes de las "torres sin fin" que el arquitecto tiene como trabajo diseñar: productor de imágenes, publicista, creador de logos. Dado que la profecía de Adolf Loos (acerca de quien Tristán Tzara decía que él era "el único [arquitecto] cuyas realizaciones no son fotogénicas"44) se cumplió: "por culpa del arquitecto, el arte de construir se ha degradado, se ha vuelto un arte gráfico". ${ }^{45}$ Esta "no real ización" fue todavía acrecentada por las nuevas técnicas de simulación basadas en las imágenes de síntesis. ${ }^{46}$

\footnotetext{
${ }^{44}$ Citado por Tournikiotis, P. (1991), Loos. París: Macula, p. 22.

${ }^{45}$ Loos, A. (1910), "Architecture", reeditado en (1931), Trotzdem, Innsbrück: Brenner Verlag (traducción al francés de C. Heim (1979), Malgrétout, París:Champ Libre, p. 122). ${ }^{46}$ Q uéau, P. (1993), Le virtuel, Le Creusot: Champ Vallon.
} 
Los objetos técnicos producidos de esta manera se inscriben en las redes territoriales. En la periferia, forman simples yuxtaposiciones sin posibilidad de articulación con los conjuntos de pequeña escala (véase en la ribera derecha del Sena en París, la adición mega-ministerio, megaestadio, supermercado). En otros lados se destruyen las antiguas ciudades y los campos inmemoriales: aquí, rincones gigantes que hacen estallar los viejos barrios (véase a Bruselas); allá, masas heterogéneas que se comen y perforan los paisajes rurales.

La arquitectura que trabajaba la escala local ha desaparecido, esa que sin importar cuáles fueran las técnicas empleadas exigía una experiencia directa de la tridimensionalidad, una entrega de cuerpo entero, aquella del arquitecto y aquella de los habitantes, que ninguna simulación puede reemplazar, puesto que la arquitectura no es una cosa mental. "Los vivos tienen un cuerpo que permite salir del conocimiento", ${ }^{47}$ nos recuerda Eupalinos. Y este cuerpo arrojado al espacio funda la "intersomaticidad"48 que a su vez funda la urbanidad. Bajo el cobijo del proyecto, y bajo la invocación de la morfología urbana y de otros "trompe-l'oeil" (efectos visuales engañosos), los arquitectos, urbanistas, administradores y las colectividades locales se obstinan en no admitir que ellos no reconocen hoy más que una sola escala de reordenamiento espacial. Sobre la nueva Babel se abate una nueva maldición: la confusión de escalas, que enreda la escena urbana y vuelve indiscernible la diferencia de los intereses en juego y de actores que aquí se confrontan.

Reino de lo urbano, supresión de la ciudad, escala única de reordenamiento: mejor que taparnos la cara frente a estas evidencias, convendría darse cuenta de sus consecuencias. Estas no son hoy mencionables más que en forma de cuestionamientos.

\footnotetext{
${ }^{47}$ Valéry, P. (1992), Eupalinos ou l'Architecte, precedido por L'Âme et la Danse. París: Gallimard, p.11.

${ }^{48}$ Expresión del filósofo italiano Dino Formaggio en (1976) Arte come idea e come esperienza, Milán: Mondadori (traducción frrancesa: (1986), L'art, París: Klincksieck).
} 
INTERROGANTES

La primera es la correspondiente a la escala local. Esta escala de urbanidad que supieron preservar Haussmann, Wagner y Cerdá y a la cual pretenden hoy los historicistas de doble cara, ${ }^{49}$ ¿es compatible con el ordenamiento reticular?, ¿es ésta compatible con el "laisserêtre"(dejar ser) de la técnica y con la evolución de las mentalidades que ésta determina? Lo urbano no es un sinónimo de urbanidad. Ésta sin embargo no es propiedad exclusiva de la ciudad. Podemos regresar entonces a Giovannoni e imaginar los núcleos de urbanidad, de tallas y de formas múltiples, susceptibles de entrar con lo urbano en una dialéctica homóloga a aquella que unía en otros tiempos la ciudad y el campo.

Pero esta hipótesis es aleatoria. Ella depende de una toma de conciencia colectiva, de una elección de sociedad; más aún, de una opción filosófica. Subsidiariamente, pero solidariamente necesita también el destino de la práctica que continúa llamándose arquitectura. ¿Sabrán nuestras sociedades redescubrir la esencia de ésta y reorganizar su enseñanza?, ¿los arquitectos volverán a aprender la experiencia tridimensional del espacio y del arte de la articulación?, ¿reencontrarán ellos el camino de la modestia para regresarle a su disciplina un papel fundador?

Todas las otras interrogantes son tributarias de la primera, incluida la de la estética. Yo me limitaré aquí a subrayar el problema de nuestras herencias. ¿La ciudad histórica, así como el campo de los pueblos y de los paisajes - que sólo forman uno hoy-, pueden ser abandonados al único consumo cultural?, ¿no es tiempo ya de volver a hacer las obras? La ciudad europea todavía tan masivamente presente, aunque tan drásticamente desgastada, debe y podría ser a la vez preservada y utilizada como obra de arte, como patrimonio social y como incitación a reencuentros con las escalas de la urbanidad. Todavía es tiempo.

49 Véase (1978), "La reconstruction de la ville européenne”, en Robert Delevoy (ed.), Architecture rationelle. Bruselas: Archives de l'architecture moderne.

186 Andamios 
Pero no hay que engañarse. La ciudad europea no se convertirá en "Collage City", ${ }^{0}$ no puede ser más un objeto que yuxtapone un estilo nuevo a aquellos del pasado. Ella no sobrevivirá más que bajo la forma de fragmentos, inmersos en la marea de lo urbano, faros y boyas de un camino a inventar.

${ }^{50}$ Rowe, C. y Koetter, F. (1978), Collage City, Cambridge Mass: mıт Press (traducción francesa: (1993), Collage city, París: Editions du Centre Pompidou). 